\title{
Successful treatment of multiple cutaneous leiomyomas with carbon dioxide laser ablation
}

\author{
Igor Michajłowski ${ }^{1}$, Izabela Błażewicz'1 ${ }^{1}$ Gabrielle Karpinsky², Michał Sobjanek ${ }^{1}$, Roman Nowicki ${ }^{1}$ \\ ${ }^{1}$ Department of Dermatology, Venereology and Allergology, Medical University of Gdansk, Gdansk, Poland \\ Head of the Department: Prof. Roman Nowicki MD, PhD \\ ${ }^{2}$ The Student Scientific Association in the Department of Dermatology, Venereology and Allergology, Medical University of Gdansk, \\ Gdansk, Poland \\ Head of the Department: Prof. Roman Nowicki MD, PhD
}

Postep Derm Alergol 2015; XXXII (6): 480-482

DOI: 10.5114/pdia.2015.48058

Leiomyomas are rare, benign neoplasms that arise from smooth muscles. The condition was first reported in 1854 by Rudolf Virchow [1, 2]. According to the site of origin we can distinguish piloleiomyoma (deriving from the arrector pili muscles of hair follicles), genital leiomyoma (originating from the tunica dartos of the scrotum, and mammary muscles of nipples), and angioleiomyoma (arising from smooth muscles of blood vessels) [3]. The most common locations include the uterus (about 95\% of cases) and the skin, which accounts for $75 \%$ of extrauterine leiomyomas [4]. According to Malhotra, the average age of onset is 38.9 years for solitary leiomyomas and 43.8 years for multiple lesions [5].

Herein we report a 41-year-old man with multiple, painful, well-demarcated, oval, red papules localized within the region of the left scapula. The lesions had appeared progressively over the past 6 months. They measured $5 \mathrm{~mm}$ to $20 \mathrm{~mm}$ and were increasing in size and number (Figure 1). The intensity of the pain was aggravated by pressure and exposure to low temperature. The level of pain was preventing him from sleeping, sitting and participating in normal everyday activities. Family history of similar lesions and physical examination were unremarkable. Based on the clinical picture we assumed multiple leiomyoma. The final diagnosis of leiomyoma was based on histopathological examination of the lesional tissue. It revealed a well-demarcated lobulated tumor located in the reticular dermis. It consisted of bundles of smooth muscle fibers. Tumor cells had eosinophilic cytoplasm and blunt-ended vesicular nuclei. There was no cytologic atypia or mitotic activity (Figure 2). Routine hematological, urine and ultrasound examination of the abdomen did not reveal any abnormalities.

Because of the huge number of leiomyomas, surgical removal was impossible. Treatment with carbon dioxide laser ablation was performed under local anesthesia with $2 \%$ lignocaine. We used the following settings: total power output $-10 \mathrm{~W}$, spot size $-1 \mathrm{~mm}$. We performed four procedures with monthly intervals and no side effects had been reported. During a 6-month follow up, the patient was completely asymptomatic and occurrence of new leiomyomas had not been noticed (Figures 1 B, C). Although the cosmetic outcome was not perfect, the resolution of pain seemed to be more important.

Cutaneous leiomyomas are benign tumors of smooth muscle bundles [4]. Piloleiomyomas are the most common type of leiomyomas. They may be either solitary or multiple. Solitary cutaneous piloleiomyomas are usually asymptomatic and larger in size. Multiple piloleiomyomas occur more often and can be inherited as an autosomal-dominant trait with variable penetrance, or they can occur spontaneously. The pathogenesis of leiomyomas remains obscure. Multiple cutaneous leiomyomas may occur in conjunction with uterine leiomyomas, also known as multiple cutaneous and uterine leiomyomatosis (MCUL), familial leiomyomatosis cutis et uteri, Reed syndrome, or multiple leiomyomatosis [2]. Some patients with Reed syndrome also were found to have aggressive forms of renal cell carcinoma, which is known as hereditary leiomyomatosis and renal cell cancer (HLRCC) [6]. In the case of our patient, the family history of similar lesions was unremarkable.

Piloleiomyomas usually present as small, red-brown, firm papules. Individual lesions range in size from few millimeters to $1 \mathrm{~cm}$ and are fixed to the skin [7]. They are freely movable over underlying deeper structures. The most common location includes the trunk and extensor surfaces of upper extremities, however, involvement of the face, breast and scrotum have also been described $[5,8]$. Various distribution patterns have been reported:

Address for correspondence: Izabela Błażewicz, Department of Dermatology, Venereology and Allergology, Medical University of Gdansk, 7 Debinki St, 80-211 Gdansk, Poland, phone: +48 791002 315, e-mail: izabela.blazewicz@wp.pl Received: 6.08.2014, accepted: 24.09.2014. 


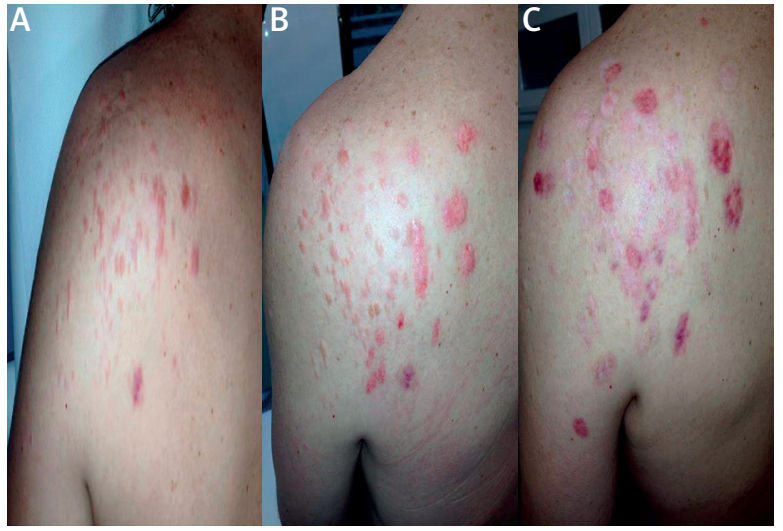

Figure 1. A - Multiple cutaneous leiomyomas within the region of the left scapula at initial presentation. $\mathbf{B}-$ The clinical appearance 1 month after the initial lesions were treated. $\mathrm{C}$ - The clinical appearance 6 months postoperative

symmetrical, Blaschkoid, diffuse (disseminated), and segmental (zosteriform) [2, 5, 9-11].

Piloleiomyomas can be asymptomatic or very painful. Approximately $50 \%$ to $72 \%$ of patients complain of pain $[5,7]$. They tend to occur more frequently in diffuse and segmental forms [2]. The origin of pain is not fully understood. It may be spontaneous or secondary to local pressure by the tumor on cutaneous nerves [3]. Other authors have suggested that it is due to muscle contraction mediated via $\alpha$-adrenergic receptors [12].

The diagnosis of pilar leiomyoma may be suspected clinically, but the final diagnosis is based on the histopathological examination of lesional tissue. It shows proliferation of smooth muscle bundles which are described as cigar-shaped. The cells have eosinophilic cytoplasm and elongated nuclei with blunt ends. They stain positively for markers of smooth muscle differentiation (desmin and actin) $[5,9,13,14]$.

In the case of solitary leiomyomas, the first line of therapy is surgical excision of tumor. Due to numerous lesions and frequent recurrences after surgical removal of multiple leiomyomas, we decided to avoid surgical procedures. Various medications have been used with diverse response to alleviate pain connected with cutaneous leiomyomas. These include calcium channel blockers $[3,10,11], \alpha$-adrenergic blocking agents [15], anticonvulsants [3], serotonin reuptake inhibitors, and topical $9 \%$ hyoscine hydrobromide, hyoscine butyl bromide. There is a single report of carbon dioxide laser ablation with significant improvement [4]. The carbon dioxide laser is the most versatile laser used in the treatment of cutaneous lesions. It is unique in that it can be used for resurfacing as well as excisional and even incisional procedures. The localized tissue destruction produced by carbon dioxide laser may make this technique superior to other destructive methods and allows the scarring to be limited. As in

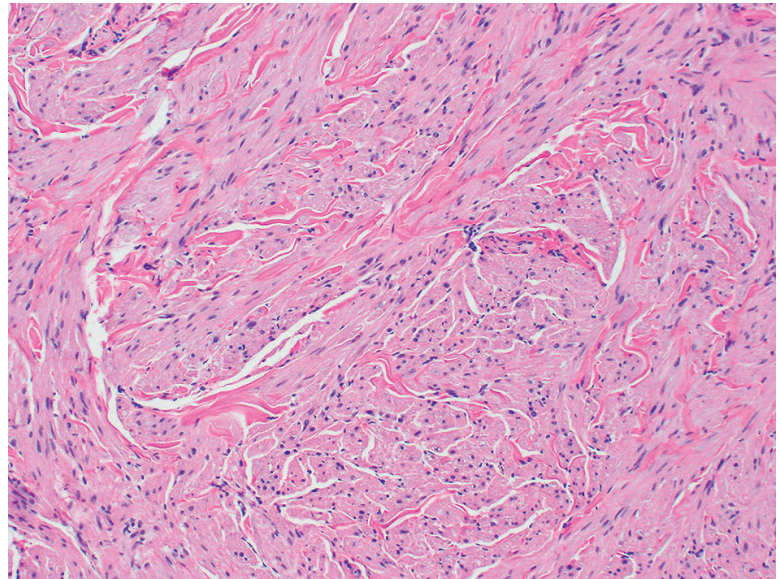

Figure 2. The histopathological examination of the lesional tissue revealed a well-demarcated lobulated tumor located in the reticular dermis. It consisted of bundles of smooth muscle fibers. Tumor cells had eosinophilic cytoplasm and blunt-ended vesicular nuclei. There was no cytologic atypia or mitotic activity

the case described by Christenson et al. [4], we observed resolution of pain in all treated lesions. Although the cosmetic outcome was not perfect, the resolution of pain seemed to be more important. The follow up period is required to assess the long-term results.

Multiple leiomyomas can arise in hundreds and because of that, surgical procedures are not a viable option. Carbon dioxide laser ablation may be one of the therapeutic options in the case of multiple and painful leiomyomas.

\section{Conflict of interest}

The authors declare no conflict of interest.

\section{References}

1. Thompson JA Jr. Therapy for painful cutaneous leiomyomas. J Am Acad Dermatol 1985; 13: 865-7.

2. Virchow R. Ueber Makroglossie und pathologische Neubildung quergestreifter Muskelfasern. Virchows Arch Pathol Anat 1854; 7: 126-38.

3. Spencer JM, Amonette RA. Tumors with smooth muscle differentiation. Dermatol Surg 1996; 22: 761-8.

4. Christenson, Smith K, Arpey CJ. Treatment of multiple Cutaneous leiomyomas with CO2 laser ablation. Dermatol Surg 2000; 26: 319-22.

5. Launonen V, Vierimaa O, Kiuru M. Inherited susceptibility to uterine leiomyomas and renal cell cancer. Proc Natl Acad Sci U S A 2001; 98: 3387-92.

6. Stewart L, Glenn G, Toro JR. Cutaneous leiomyomas: a clinical marker of risk for hereditary leiomyomatosis and renal cell cancer. Dermatol Nurs 2006; 18: 335-41.

7. Holst VA, Junkins-Hopkins JM, Elenitsas R. Cutaneous smooth muscle neoplasms: clinical features, histologic findings, and treatment options. J Am Acad Dermatol 2002; 46: 477-90. 
8. Sahoo B, Radotra BD, Kaur I. Zosteriform pilar leiomyoma. J Dermatol 2001; 28: 759-61.

9. Smith G, Heidary N, Patel R. Cutaneous piloleiomyomata. Dermatol Online J 2009; 15: 10.

10. Ghanadan A, Abbasi A, Kamyab Hesari K. Cutaneous leiomyoma: novel histologic findings for classification and diagnosis. Acta Med Iran 2013; 51: 19-24.

11. Aggarwal S, De D, Kanwar AJ. Disseminated cutaneous leiomyomatosis treated with oral amlodipine. Indian J Dermatol Venereol Leprol 2013; 79: 136.

12. Fisher WC, Helwig EB. Leiomyomas of the skin. Arch Dermatol 1963; 88: 510-20.

13. Sherwani RK, Rahman K, Akhtar K. Leiomyoma of scrotum. Indian J Pathol Microbiol 2008; 51: 72-3.

14. Dilek N, Yüksel D, Sehitoğlu I. Cutaneous leiomyoma in a child: a case report. Oncol Lett 2013; 5: 1163-4.

15. Suwattee P, Dakin C. Bilateral segmental leiomyomas: a case report and review of the literature. Cutis 2008; 82: 33-6. 